\title{
Low Frequency Multi-Level Switching Strategy Based on Phase-Shift Control Methods
}

\author{
Sang-Hun Lee *, Sung-Geon Song** and Sung-Jun Park***
}

\begin{abstract}
In this paper, we propose an electric circuit using one common-arm of H-Bridge inverters to reduce the number of switching components in the multi-level inverter combined with H-Bridge inverters and transformers. And furthermore, we suggested a new multi-level PWM inverter using PWM level to reduce THD (Total Harmonic Distortion). We use a phase-shift switching method that has the same rate of usage at each transformer. Also, we test the proposed prototype 9-level inverter to clarify the proposed electric circuit and reasonableness of the control signal for the proposed multi-level PWM inverter.
\end{abstract}

Keywords: H-Bridge Inverter, THD (Total Harmonic Distortion), phase-shift switching method

\section{Introduction}

Recently reduction of total harmonic distortion in an inverter has been researched using a multi-level inverter [1]-[11]. In proportion to the increase of output voltage level of the multi-level inverter, the number of switching elements was increased. However, because it has less harmonic distortion and smaller $d t / d v$, it is widely applied to industrial applications instead of the existing PWM (pulse width modulation) inverter. An isolated multilevel inverter using a common-arm is proposed to replace HBML (H-Bridge multi-level) that needs a number of independent power supplies and switching components [12] The isolated multi-level inverter of H-Bridge inverter and transformer combined reduces the number of the switching components less than a non-isolated inverter. But, when the same transformer of the non-isolated inverter is used, the switching frequency is increased [13]-[14].

In this paper, a novel phase-shift control method is proposed to reduce the switching frequency of the common-arm type isolated multi-level inverter using the same transformers. The proposed switching method keeps up the same switching frequency using step pulse wave method so that each arm of the inverter generates only one switch per base frequency. To evaluate the proposed switching method, we simulate the each switching pattern

\footnotetext{
* Dept. of Electrical Design, Korea Lift College, Korea. (purme@klc.ac.kr)

** Digital Convergence Research Center, KETI, Korea (sgsong@keti.re.kr)

*** Dept. of Electrical Engineering, Chonnam National University, Korea. (sjpark1@chonnam.ac.kr)
}

Received 30 July 2012; Accepted 18 August 2012 of the multi-level inverter using the same existing transformer and a novel phase-shift control method. And we make and test isolated $3 \mathrm{~kW}$ prototype multi-level inverter using the common-arm.

\section{Multi-level inverter using transformer}

\subsection{Isolated multi-level inverter using an existing common-arm}

Fig. 1(a) shows the isolated multi-level inverter of $\mathrm{H}$ bridge circuits and transformer combined. In Fig. 1(a), the primary coil of the transformer parallels with the power voltage and the secondary coil is serial with it [5]. Each Hbridge inverter generates dc-link voltage of positive, negative, and zero according to the switching function. And the end output voltage $V_{O}$ is the sum of output voltage of each H-bridge that is connected to the serial. In Fig. 1(b), output of each H-bridge inverter in the isolated HBML inverter using transformer is determined by the command voltage polar. In the case of $\mathrm{H}$-bridge that is in charge of the voltage level, the inverted polar is not generated in the same command voltage polar domain. The arm signal that determines the polar is classified in the inverter to have this condition. If the signal determining the polar is the same and the same DC-link voltage is used, the arm of each $\mathrm{H}$ bridge can be shared. Therefore, Fig. 1(b) shares the arm of each H-bridge in Fig. 1(a). So we can reduce the number of components on one side of the H-bridge arm that is in charge of the polar of voltage [7]-[8]. 


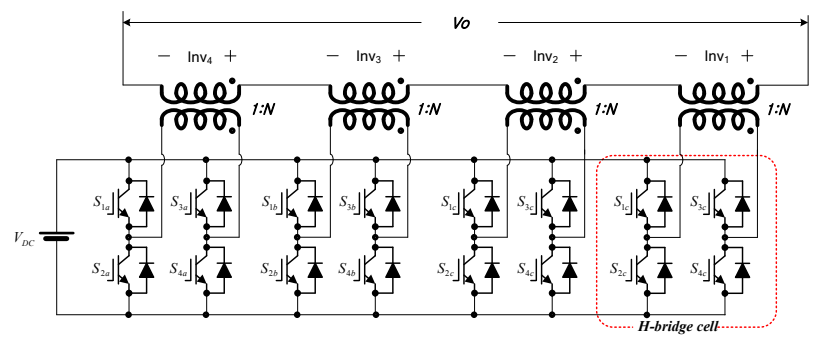

(a) Transformer type HBML inverter.

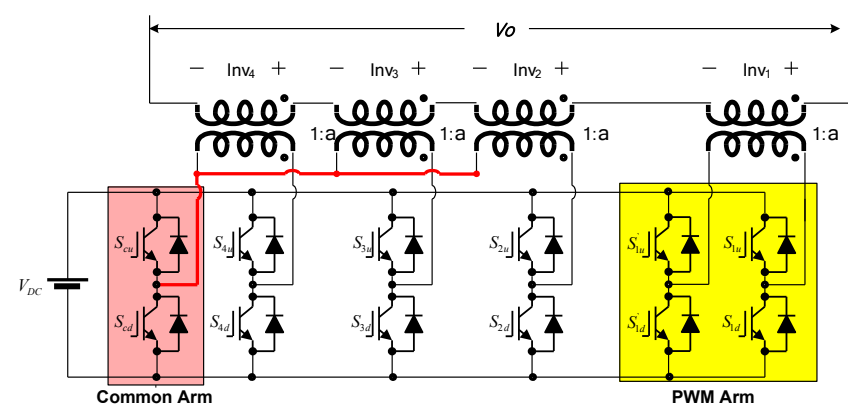

(b) The improved HBML inverter using the common-arm

Fig. 1. Configuration of 9-level HBML inverter using transformers.

\subsection{Multi-level switching signal for utilization coefficient of existing same transformer}

Fig. 2(a) shows switching periods of voltage and voltage level section is permitted to each transformer to positive command voltage.

When we use the same transformer, the switching pattern based on the switching function using the step pulse wave method generates switching function subdivided so as to have the same voltage integral that is permitted to each transformer. The switching method to have the same utilization coefficient is many, but the base method is the same. Fig. 2(b) shows the switching periods of each level. The period $T_{m}$ that is permitted to each level is divided by the number of inverter $N$. It is the subdivided period.

$$
T_{n m}=\frac{T_{m}}{N}
$$

In each level $N$ is permitted to the periods $T_{n m}$, to make the same width of the permitted voltage, switching interval in each level is divided by the number of transformer to make the $N$ unit of the positive voltage. It is switched alternately. When the proposed method is used, the maximum magnetic flux of each transformer is the same. The switching method in Fig. 2 has the disadvantage that the switching frequency is increased to the same capacity of each transformer.

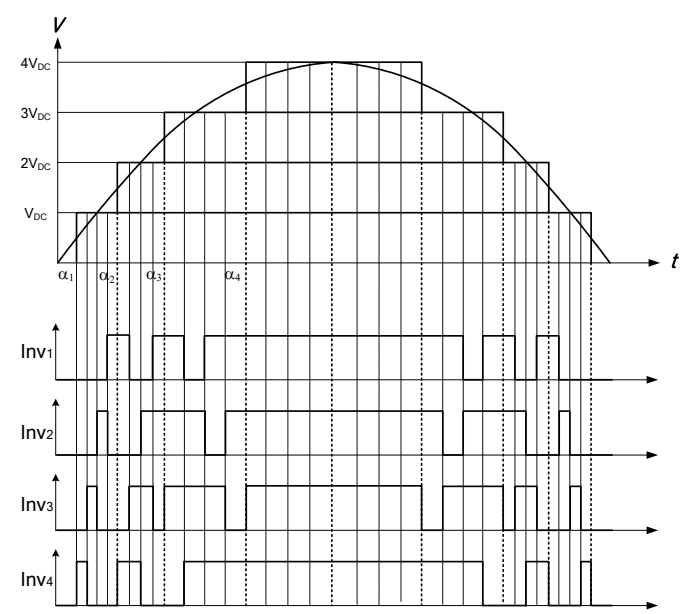

(a) Switching pattern.

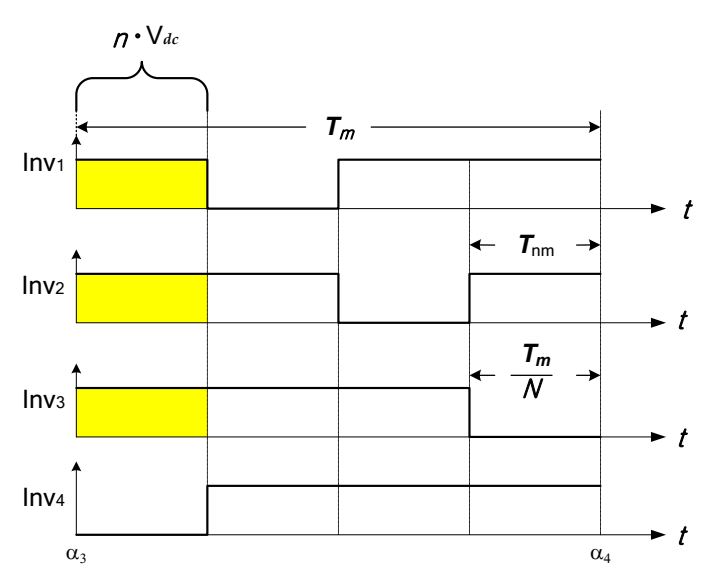

(b) Switching period to voltage level period.

Fig. 2. The switching function of HBML inverter using the same rating transformers.

\subsection{A novel switching signal using phase shift control methods}

Fig. 3 shows the switching signal of HBML inverter using phase shift control methods that has 4 transformers. The switching signal of each inverter determines the sequence of inverters turned off according to the sequence of inverters turned on. The proposed switching method reduces the switching frequency in a common-arm type isolated multi-level inverter using the same transformer can keep up the same switching frequency using step pulse wave method that adapts phase shift control method.

Fig. 3 shows the basic concept to generate switching frequency that determines dwell angle of each inverter using phase shift control method in a multi-level inverter. 
The intersection point of the voltage of each level and the sinusoidal command voltage is the same with the existing multi-level inverter.

$$
\theta_{n}=\sin ^{-1}\left(\frac{n V_{D C}}{V_{p}}\right)
$$

If the intersection point $n$ that satisfies (2) exists, the dwell angle of inverter is determined by the following equation.

$$
\alpha_{n}=\theta_{n}-\frac{1}{V_{D C}} \int_{\theta_{n-1}}^{\theta_{n}}\left(V_{P} \sin \theta-n V_{d c}\right) d \theta
$$

where $\theta_{0}=0$.

If (2) is not satisfied, dwell angle of $n_{\text {-th inverter is }}$ determined by the following equation.

$$
\alpha_{n}=\frac{\pi}{2}-\frac{1}{2 V_{D C}} \int_{\theta_{n-1}}^{\pi-\theta_{n-1}}\left(V_{P} \sin \theta-n V_{d c}\right) d \theta
$$

The angle of extinction is determined by the following equation.

$$
\beta_{n}=180-\alpha_{N-n}
$$

where $N=$ the total number of level voltage.

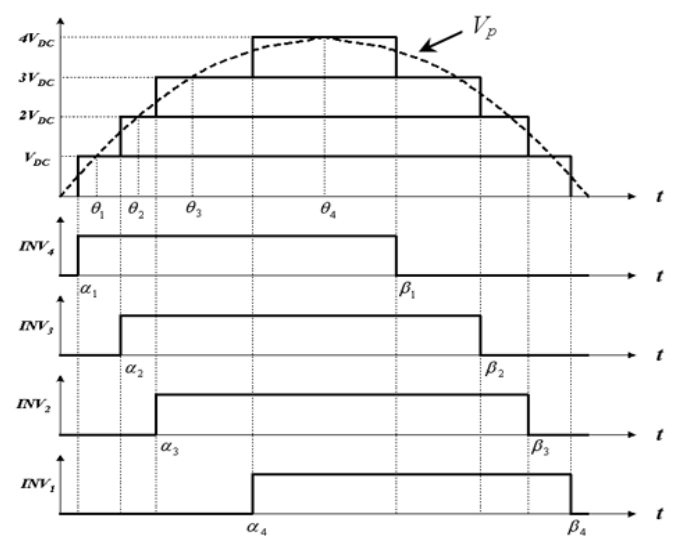

Fig. 3. Multi-level switching strategy based on phase-shift control.

\section{Simulation and test result}

To evaluate the switching pattern of the proposed multilevel inverter, the transformer combination and switching frequency permitted to each transformer module is confirmed by simulation through specification in Table 1 . To use the same transformer, the switching frequency is simulated to confirm utilization coefficient of the same transformer based on 1:1:1:1 transformer. And PWM 9level inverter of 1 transformer to PWM and 1:1:1 multilevel inverter combined is tested.

Fig. (4) shows the output voltage and command voltage of PWM hybrid 9-level inverter that has exclusive PWM module and output wave of each transformer. The voltage level of 9-level inverter can be increased to a maximum 15level using 1 transformer that is an exclusive PWM module.

The switching frequency of each transformer module, in case of 9-level inverter, is constant.

Table 1. Parameters of the Experimental Setup

\begin{tabular}{ll}
\hline Specification & Condition \\
\hline Output voltage & $220[\mathrm{~V}]$ \\
\hline Input voltage & $55[\mathrm{~V}]$ \\
\hline Power & $3[\mathrm{~kW}]$ \\
\hline Load capability & $3[\mathrm{kVA}]$ \\
\hline Load efficiency & $80[\%]$ \\
\hline
\end{tabular}
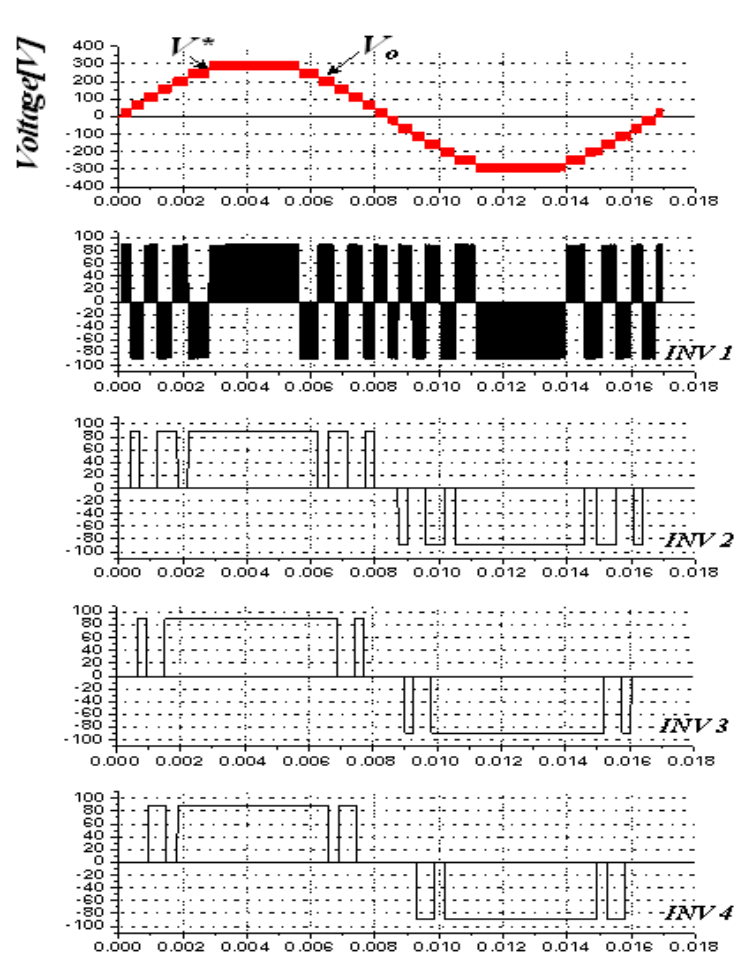

Time [ms]

Fig. 4. The simulation output voltage $\&$ wave form of each transformer of 9-level PWM inverter (the same utilization coefficient of transformer). 
The switching frequency of $I N V_{2}$ transformer module is higher than that of $I N V_{3}$ and $I N V_{4}$ Therefore, to solve this problem, the module having the higher switching frequency is changed in each period. Fig. (5) show 9-level multi-level inverter using phase-shift control method and hybrid PWM 9-level inverter that reduces the switching frequency in the existing same transformer.
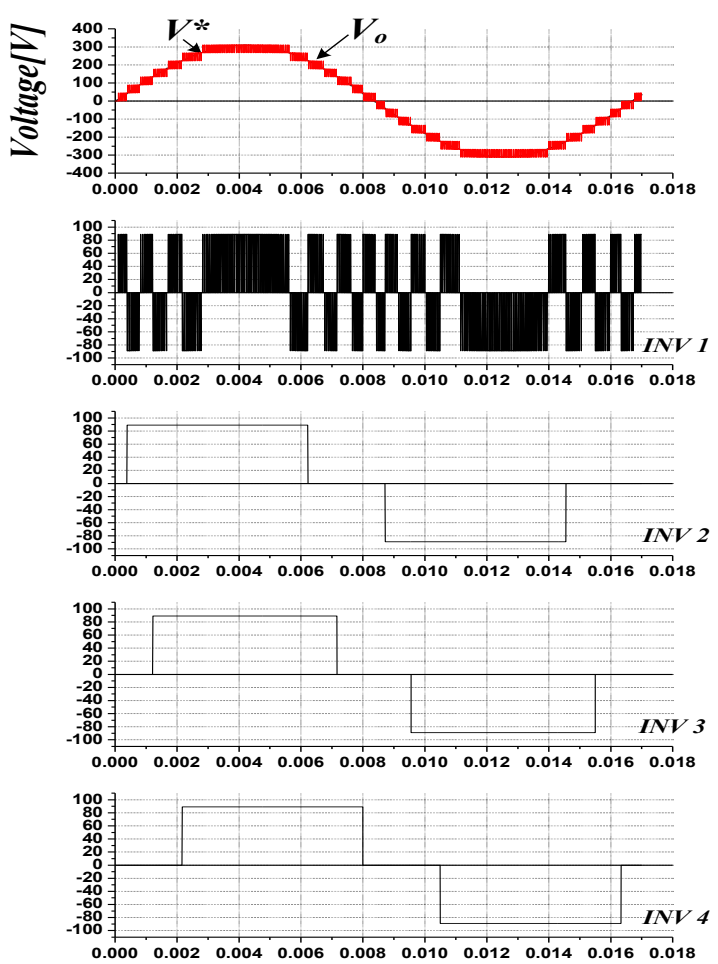

Time[ms]

Fig. 5. The simulation output voltage \& wave form of each transformer of 9-level PWM inverter (phase shift control method).

Fig. 6(a) shows the controller part to control the output of multi-level inverter and the power stack part that supplies power to the transformer. The process to control the multi-level inverter is DSP (TMS320F2812) in Fig. 6(b) and the sampling frequency is $15[\mathrm{kHz}]$ using $\mathrm{A} / \mathrm{D}$ interrupter of timer 1 overflow method. The analog circuit is constructed to detect input and output voltage and current of multi-level inverter using op-amp TL084. And A/D converter of the DSP detects the voltage and the current. On-off signal of each switching component is controlled by 10 PWM terminal of the DSP. To prevent arm short, the dead time is set by 5 [S]. Fig. 6(c) shows the power stack part of the multi-level inverter and the gate amp to supply the controlled signal.

Fig. 7 displays the phase switch signal of each arm, switch signal of common-arm and the command value of output voltage in 9-level inverter having 4 transformers using phase shift control method when the modulation index is 1 .

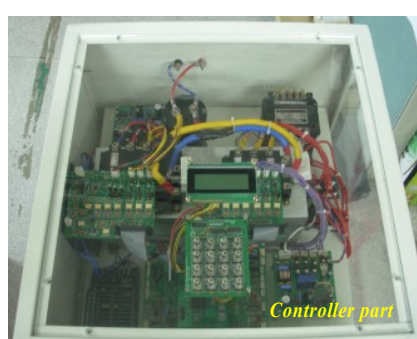

(a) Control part

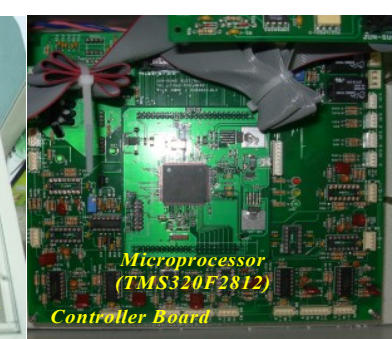

(b) Microprocessor part

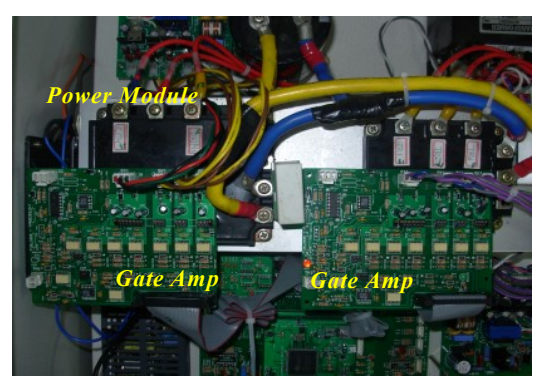

(c) Power stack part.

Fig. 6. The control part composition.

The switching frequency is the same to the step pulse wave method that switches 1 per base frequency. And the switching signal of the common-arm generates the phase switching signal that is the same with the existing switching signal according to the polar of the command voltage. Therefore, for half period of positive signal, the switching pattern in the switching frequency of each H-bridge module is reduced by using the proposed phase shift control method.

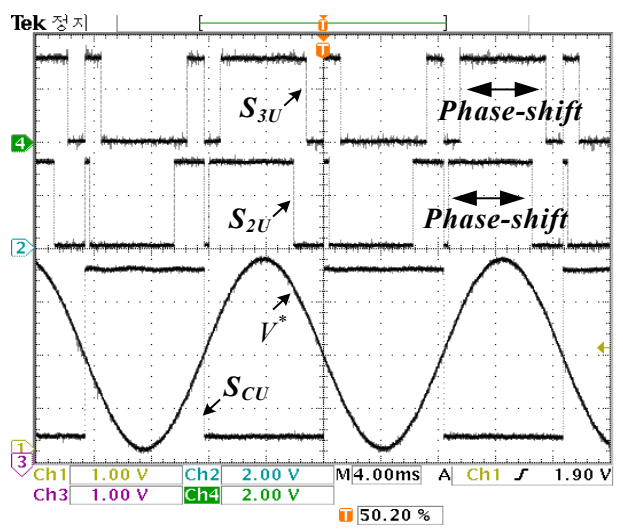

Fig. 7. Common-arm \& each switching signal.

In order to analysis the characteristic the common-arm, 
Fig. 8 shows the output wave of each arm and the difference between wave of the common-arm and wave of another arm. When we use the phase shift control method, the multi-level characteristic to generate the output voltage is the same as the existing switching pattern to generate multi-level. And, according to the polar of the common-arm, the polar of the output voltage is the same. Fig. 8 shows each wave of the multi-level inverters that are serially connected. And the polar of the output voltage is the same according to the polar of the common-arm.

Fig. 9 shows each wave of the multi-level inverter that is serially connected when gate signal of each inverter is permitted.

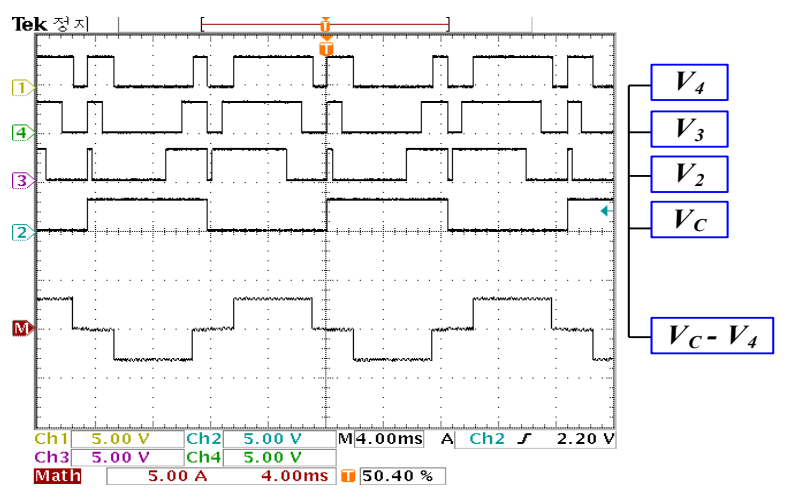

Fig. 8. The output of each arm.

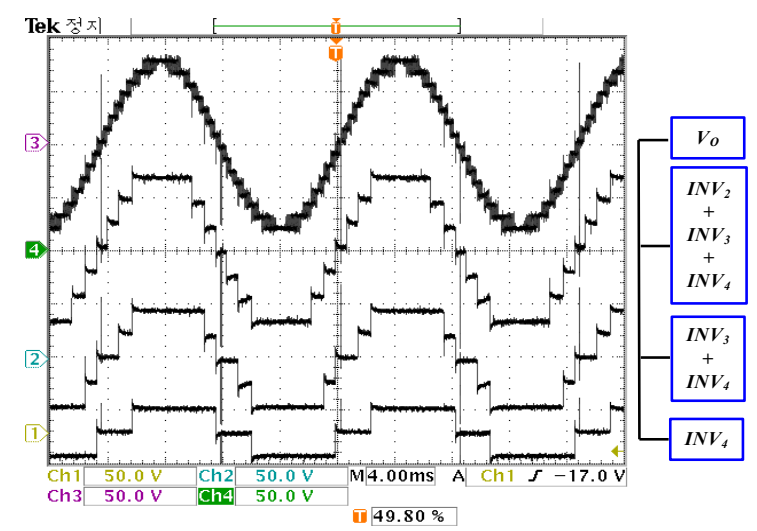

Fig. 9. Each wave form of multi-level inverter.

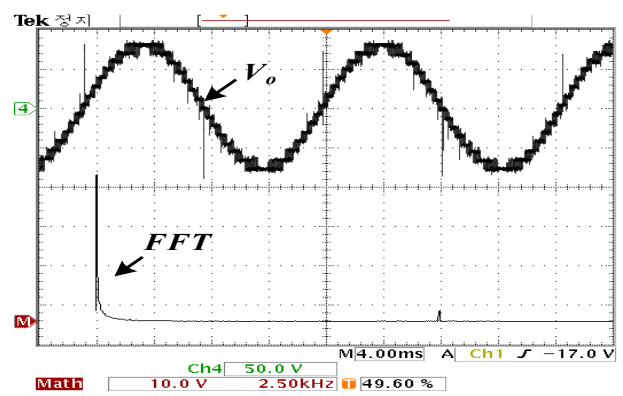

Fig. 10. The output voltage \& FFT analysis.
The most below wave in Fig. 9 is the output voltage of 1 transformer, and the above waves are the output wave of 2 , 3 , and 4 serial transformer. The output voltage has 15 levels Fig. 10 shows the output voltage and the harmonic distortion analysis of the output voltage.

\section{Conclusion}

In this research, a common-arm of each inverter is used for reducing the switching components of a multi-level inverter of H-bridge inverter and transformer combined. The capacity of the transformers that generate the level is equalized using the switching method that makes the same coefficient utilization of the transformer connected to each inverter.

To use the same transformer, the switching frequency of the switching pattern that controls the sum of integral for each level increases. So the proposed phase-shift control method keeps the switching frequency up and it is the same frequency of the step pulse wave method that switches once per base frequency.

To evaluate the proposed switching pattern using the phase-shift control, simulation results are presented. And the experimental system was set up using a prototype of 9level inverter.

\section{References}

[1] J. I. Rodriguez and S. B. Leeb, "A multilevel inverter topology for inductively coupled power transfer," IEEE Trans. Power Electron., vol. 3. no. 6, pp. 1607-1617, Nov. 2006.

[2] H. M. Kojabadi, Bin Yu, I. A. Gadoura, Liuchen Chang, and M. Ghribi, "A novel DSP-based current-controlled PWM strategy for single phase grid connected inverters," IEEE Trans. Power Electron., vol. 21, no. 4, pp. 985-993, July 2006

[3] B. P. McGrath, D. G. Holmes, and T. Meynard, "Reduced PWM harmonic distortion for multilevel inverters operating over a wide modulation range," IEEE Trans. Power Electron., Vol. 21, no. 4, pp. 941-949, July 2006.

[4] T. Abeyasekera, C. M. Johnson, D. J. Atkinson, and M. Armstrong, "Suppression of line voltage related distortion in current controlled grid connected inverters," IEEE Trans. Power Electron., vol. 20, no. 6, pp. 1393-1401, Nov. 2005.

[5] J. Rodriguez, L. Moran, J. Pontt, P. Correa, and C. Silva, "A high-performance vector control of an 11-level inverter," IEEE Trans. Ind. Electron., vol. 50, no. 1, pp. 80-85, Feb. 2003.

[6] J. Rodriguez, L. Moran, P. Correa, and C. Silva, "A vector control technique for medium-voltage multilevel inverters," IEEE Trans. Ind. Electron., vol. 49, no. 4, pp. 882-888, Aug. 2002.

[7] S. Fukuda, and K. Iwaji, "Introduction of the harmonic distortion determining factor and its application to evaluating real time PWM inverters," IEEE Trans. Ind. Appl., vol. 31, no. 1, pp. 149-154, Jan. 1995. 
[8] A. I. Pressman, Switching power supply design, McGrawHill, Inc., 1991.

[9] N. Mohan, T. M. Undeland, and W. P. Robbins, Power electronics: converters, applications, and design, John Wiley \& Sons, Inc., 1995.

[10] B. K. Bose, Power electronics and variable frequency drives: technology and applications, IEEE Press, 1997.

[11] F. S. Shyu, and Y. S. Lai, "Virtual Stage Pulse-Width Modulation Technique for Multilevel Inverter/Converter," IEEE Trans. Power Electron., vol. 17, no. 3, May 2002.

[12] J. Dixon, and M. Rotella, "PWM method to eliminate power sources in a non-redundant 27-level inverter for machine drive application", in Proc. IEEE Ind. Electron. Conf., 2006, vol. 2, pp. 1094-1099.

[13] Y. Tao, C. J. Moon, S. J. Park and S. G. Song and J. M. Lim, "A study on novel PWM HBML inverter using commonarm," in Proc. IEEE Ind. Tech. Conf., 2006, pp. 1287-1292.

[14] Y. Tao, J. G. Jean, S. J. Park, J. H. Chung, S. C. Yang, and C. J. Moon, "A study on the HBML inverter using the cascaded transformers," in Proc. IEEE PEDS Conf., 2005, vol. 2, pp. 994-998.

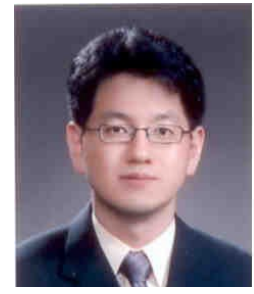

Sang-Hun Lee was born in Busan, Korea, in 1974. He received his B.S and M.S. degrees in Electrical Engineering from KyungSung University, Busan, Korea, in 2000, 2002, respectively. He received his $\mathrm{Ph} . \mathrm{D}$ degrees in Mechatronics Engineering from Pusan National University, Busan, Korea, in 2006. He worked a Junior Researcher of Technology\& Researcher at KTE, from 2002 to 2004, He has been with Kyungsung University, Busan, Korea, as a Researcher in the Advanced Electric Machinery \& Electronics Center since 2006. His major research field is Electrical Motor Drive with Power Electronics.

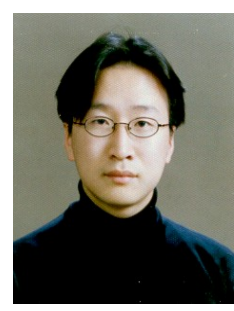

Song Sung Geun was born in GwangJu, Korea. He received the B.S., M.S. and $\mathrm{Ph} . \mathrm{D}$ degrees in electrical engineering from Chonnam National University, in 1998, 2000 and 2007, respectively. From 2001 to 2004, he was a Research Scientist at PROCOM system, Ltd., From 2004 to 2005, he was a Research Scientist at SEO ELECTRONICS CO., LTD. Since 2008, he is working in KETI(Korea Electronics Technology Institute), where he is currently Gwang-Ju Regional Headquarter. His fields of interest are power electronics, motor drives, digital signal processing, tractions, and their control system.

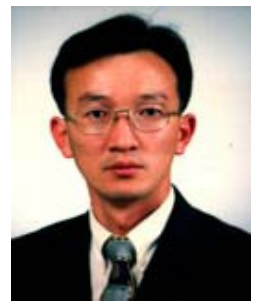

Sung-Jun Park received the B.S., M.S., and Ph.D. degrees in electrical engineering from Pusan National University, Busan, Korea, in 1991, 1993 and 1996, respectively, where he also received the Ph.D. degree in mechanical engineering in 2002.From 1996 to 2000, he was an Assistant Professor with the Department of Electrical Engineering, Koje College, Koje, Korea. From 2000 to 2003, he was an Assistant Professor with the Department of Electrical Engineering, TongMyong College, Busan. Since 2003, he has been with the Department of Electrical Engineering, Chonnam National University, Gwangju, Korea, as an Associate Professor. His research interests include power electronics, motor control, mechatronics, micromachine automation, and robotics. Dr. Park is a member of The Korean Institute of Electrical Engineers and The Korean Institute of Power Electronics. 